\title{
Synthesis and characterization of mesoporous materials with SBA and MCM structure types
}

\author{
(Síntese e caracterização de materiais mesoporosos \\ de estruturas dos tipos SBA e MCM)
}

\author{
R. A. Sacramento ${ }^{1 *}$, O. M. S. Cysneiros ${ }^{1}$, B. J. B. Silva ${ }^{1}$, A. O. S. Silva ${ }^{1}$ \\ ${ }^{1}$ Federal University of Alagoas, Laboratory of Synthesis of Catalysts, 57072-900, Maceio, AL, Brazil
}

\begin{abstract}
Mesoporous materials are promising structures for application in catalysis and adsorption due to high surface area and large pore size. Mesoporous materials were synthesized by the hydrothermal method with novel surfactants, distinct from those observed in the literature, in order to carry out a study of its structure and to obtain materials with better textural properties. The structures synthesized with the surfactants Igepal CO630 and Brij O20 presented the best results of specific surface area, 1074 and 1075 $\mathrm{m}^{2} \cdot \mathrm{g}^{-1}$, respectively. The obtained materials were characterized by XRD, TG/DTG, $\mathrm{N}_{2}$ adsorption-desorption, and FTIR techniques. XRD patterns indicated that the highly ordered mesoporous silica structures, such as MCM-41 and MCM-48, using CTMABr as the structure-directing agent and the SBA-15, SBA-16 and other SBA structures using different block copolymers were obtained. Through $\mathrm{N}_{2}$ adsorption-desorption isotherms, it was observed type IV isotherms, attributed to mesoporous materials. The FTIR spectra presented similar behaviors with characteristic vibrational bands of MCM and SBA type materials.

Keywords: mesoporous materials, synthesis, characterization.
\end{abstract}

\section{Resumo}

Materiais mesoporosos são estruturas promissoras para aplicação em catálise e adsorção devido à elevada área superficial e grande tamanho dos poros. Materiais mesoporosos foram sintetizados pelo método hidrotérmico com novos surfactantes, distintos daqueles observados na literatura, a fim de realizar um estudo de sua estrutura e obter materiais com melhores propriedades texturais. As estruturas sintetizadas com os surfactantes Igepal CO630 e Brij O2O apresentaram os melhores resultados de área superficial específica, 1074 e $1075 \mathrm{~m}^{2} . \mathrm{g}^{-1}$, respectivamente. Os materiais obtidos foram caracterizados por meio das técnicas de DRX, TG/DTG, adsorção/dessorção de $N_{2}$ e FTIR. Os padrões de DRX indicaram a obtenção de estruturas de sílica mesoporosas altamente ordenadas, tais como a MCM-41 e MCM-48, utilizando CTMABr como agente direcionador de estrutura e as estruturas SBA-15, SBA-16 e outras estruturas SBA utilizando diferentes copolímeros em bloco. As isotermas de adsorção/dessorção de $\mathrm{N}_{2}$ apresentaram isotermas do tipo IV, atribuídas a materiais mesoporosos. Os espectros de FTIR apresentaram comportamentos semelhantes com bandas vibracionais características dos materiais do tipo MCM e SBA.

Palavras-chave: materiais mesoporosos, síntese, caracterização.

\section{INTRODUCTION}

Since the development of the M41S mesoporous silica family by Beck et al. [1], with the main structures of MCM-41, MCM-48 and MCM-50, there was a significant increase in the number of publications related to the synthesis of mesoporous silica materials, and modification and application of these materials mainly as catalysts support and adsorbents, because they have a highly ordered mesostructure, high surface area, and considerable thermal and hydrothermal stability [2]. Synthesis of mesoporous silicas is generally carried out in aqueous, acidic or basic, medium, employing a solvent (water and/or ethanol), a silica

*raisa_as@hotmail.com

Dhttps://orcid.org/0000-0001-6908-6058 precursor and an organic structure (surfactant) agent. There are several synthesis methods for these materials, however the sol-gel method is one of the most used and comprises the preparation of a solution, followed by its gelation and the subsequent removal of the solvent and the organic agent [3]. The synthesis of the M41S family usually employs cationic surfactants in basic media, obtaining a matrix with uniform mesopores, ranging in size from 2 to $10 \mathrm{~nm}$ [4]. Surfactants act as a template to form the final mesoporous structure; these amphiphilic copolymers consist of two distinct regions within the same molecule, one hydrophilic (polar) end, and the other (non-polar) hydrophobic end. This feature causes the molecules in solution to self-organize in a way that minimizes contact with incompatible ends [5].

MCM-41 is morphologically described as an ordered phase having a hexagonal arrangement of unidirectional and non-interconnected pores (spatial group p6mm) [6]. 
MCM-48 has a cubic phase formed by a three-dimensional pore system (spatial group Ia3d) and MCM-50 consists of a stabilized lamellar phase with high packing factor (spatial group p2). The formation of MCM-48 is related to the mesophase transformations, which is initially not cubic, being this transformation dependent on $\mathrm{pH}$, surfactant content and silica source [7]. In 1998, Zhao et al. [8] developed the highly ordered mesoporous SBA (Santa Barbara Amorphous) family with pore size varying from 2 to $30 \mathrm{~nm}$, synthesized under acidic conditions and nonionic surfactant as a directing agent. SBA-15 is one of the most important materials of the SBA group, synthesized in an acid medium using the non-ionic triblock copolymer Pluronic P123 as a surfactant. SBA-15 has a hexagonal structure (p6mm) similar to the MCM-41, but the mesoporous silica SBA-15 presents greater hydrothermal stability due to the thicker silica walls ( 3.1 to $6.4 \mathrm{~nm}$ ) and has larger pores (4.6 to $30 \mathrm{~nm}$ ) when compared to the MCM-41 mesostructure. In addition, its hexagonal structure has a combination of micro and mesopores. The micropores correspond to up to $30 \%$ of the total pore volume and are originated from the penetration of the hydrophobic end of the surfactant into the silica walls as the organic-inorganic compound is formed [9]. SBA-16 is another mesoporous material of the SBA family, having a cubic mesoporous phase $(\mathrm{Im} 3 \mathrm{~m})$ that has a spherical cage structure. This cubic mesostructure was synthesized by applying the same synthetic route of SBA-15, in acidic medium, but using the triblock copolymer Pluronic F127 as surfactant.

As these materials are important within their class (mesoporous materials) and even with similar synthesis procedure, the type of surfactant favors the formation of specific mesostructured silica, which totally modifies their structural and textural characteristics. The aim of the present study was to synthesize and characterize mesoporous materials using different surfactants and block copolymers (not reported in the literature or without any description such as Brij 93, Brij O20 and Igepal CO630) in acidic media. These organic compounds can be used to obtain materials with different pore arrangements (hexagonal, cubic, lamellar) and different textural properties (specific surface area, pore volume, pore diameter).

\section{EXPERIMENTAL}

Hydrothermal synthesis of SBA type mesoporous structures: the SBA-15 structure (M1 sample) was synthesized according to the methodology proposed in [8]. The synthesis gel was prepared using the following molar composition: $1.0 \mathrm{SiO}_{2}: 0.017 \mathrm{P} 123: 5.6 \mathrm{HCl}: 174 \mathrm{H}_{2} \mathrm{O}$. The synthesis procedure consisted of: I) preparation of a solution containing $59.94 \mathrm{~g}$ of $\mathrm{HCl}$ (Synth) and $306.72 \mathrm{~g}$ of distilled water, where $10.71 \mathrm{~g}$ of the triblock copolymer P123 (Sigma Aldrich) was dissolved under stirring for 30 min (solution I); II) $22.63 \mathrm{~g}$ TEOS (Sigma-Aldrich) was slowly added to solution I and the mixture was kept under stirring at $40{ }^{\circ} \mathrm{C}$ for $20 \mathrm{~h}$. The obtained synthesis gel was placed in a Teflon autoclave jacketed in stainless steel and taken to an oven maintained at $100{ }^{\circ} \mathrm{C}$ for $24 \mathrm{~h}$. The SBA-16 structure (M2 sample) was synthesized using the triblock copolymer F127 (Sigma Aldrich), from a gel with the following molar composition: $1.0 \quad \mathrm{SiO}_{2}: 0.008$ F127:5.6 HCl:174 $\mathrm{H}_{2} \mathrm{O}$. Other mesoporous SBA structures were synthesized using other non-ionic triblock copolymers such as Igepal CO630 (Sigma-Aldrich), Brij O20 (Sigma-Aldrich) and Brij 93 (Sigma-Aldrich), named M3, M4, and M5 samples, respectively, following the methodology described above, by modifying only the organic agent.

Hydrothermal synthesis of MCM type mesoporous structures: the MCM-41 structure (M6 sample) was prepared according to the methodology in [10], from a gel with the following molar composition: $3.3 \mathrm{CH}_{3} \mathrm{CH}_{2} \mathrm{OH}: 1.0$ $\mathrm{SiO}_{2}: 0.5 \quad \mathrm{Na}_{2} \mathrm{O}: 0.2 \quad$ CTMABr:0.4 $\quad \mathrm{H}_{2} \mathrm{SO}_{4}: 143 \quad \mathrm{H}_{2} \mathrm{O}$. The procedure for obtaining the synthesis gel consisted of the following steps: I) mixture of $21.60 \mathrm{~g}$ of ethanol (Dynamic, $99.8 \%), 10.04 \mathrm{~g}$ of cetyltrimethylammonium bromide CTMABr (Sigma-Aldrich) and $69.12 \mathrm{~g}$ of distilled water, stirring until complete solubilization; II) dissolution of $17.25 \mathrm{~g}$ of sodium metasilicate (Carlos Erba) in $207.35 \mathrm{~g}$ of distilled water; solutions I and II were mixed and shaken for $30 \mathrm{~min}$ to obtain a homogeneous gel; III) $5.71 \mathrm{~g}$ of sulfuric acid (Merck) was diluted with $69.12 \mathrm{~g}$ of distilled water (solution III) and the mixture was added dropwise to solution obtained in step II under stirring for $90 \mathrm{~min}$ at room temperature. The final gel was transferred to a Teflon vessel jacketed in stainless steel autoclave and heated in an oven at $150{ }^{\circ} \mathrm{C}$ for $24 \mathrm{~h}$. The MCM-48 structure (M7 sample) was prepared according to the methodology presented in [11], from a gel with the following molar composition: 1.0 $\mathrm{SiO}_{2}: 0.1 \mathrm{Na}_{2} \mathrm{O}: 0.2 \mathrm{CTMABr}: 50 \mathrm{H}_{2} \mathrm{O}$. The procedure for obtaining the synthesis gel consisted of the following steps: I) $1.33 \mathrm{~g}$ of NaOH (Sigma-Aldrich) was dissolved in $76.31 \mathrm{~g}$ of distilled water, then $34.03 \mathrm{~g}$ of orthosilicate (TEOS) was added to the $\mathrm{NaOH}$ solution, under stirring at $60^{\circ} \mathrm{C}$ for $2 \mathrm{~h}$; II) $12.03 \mathrm{~g}$ of CTMABr (Sigma-Aldrich) was added in 76.31 $\mathrm{g}$ of distilled water, with stirring until the organic structure driver dissolved. Then, solution II was added to the solution I under stirring for $30 \mathrm{~min}$. The obtained gel was transferred to a Teflon vessel jacketed in stainless steel autoclave and heated in an oven at $150^{\circ} \mathrm{C}$ for $24 \mathrm{~h}$. All the materials with MCM and SBA structures were calcined in an atmosphere of synthetic air with a flow rate of $100 \mathrm{~mL} \cdot \mathrm{min}^{-1}$ at $550{ }^{\circ} \mathrm{C}$ for $6 \mathrm{~h}$. The calcination temperature was previously identified by thermogravimetric (TG/DTG) analysis to ensure complete removal of the organic compounds.

Characterization: X-ray powder diffraction analysis was done with a Shimadzu XRD-6000 diffractometer with $\mathrm{CuK} \alpha(\lambda=0.1542 \mathrm{~nm})$, Ni filter, $40 \mathrm{kV}$ voltage and $30 \mathrm{~mA}$ current. The data were obtained in the $2 \theta$ range between $0.5^{\circ}$ and $10^{\circ}$, with goniometer speed of $2^{\circ} \cdot \mathrm{min}^{-1}$ and step of $0.02^{\circ}$. Nitrogen adsorption-desorption isotherms were obtained with a Micromeritics ASAP 2020 equipment. Samples were previously degassed for $12 \mathrm{~h}$ under vacuum $(2 \mu \mathrm{mHg})$ at $350{ }^{\circ} \mathrm{C}$. The specific surface area $\left(\mathrm{A}_{\mathrm{BET}}\right)$ was 
calculated by the BET method in the range of $\mathrm{P} / \mathrm{P}_{0}=0.01$ to 0.99 , the mesoporous volume $\left(\mathrm{V}_{\mathrm{p}}\right)$ was determined by the t-plot method and the mean pore diameter $\left(\mathrm{D}_{\mathrm{BJH}}\right)$ and the pore diameter distribution was obtained from the adsorption isotherm curve by the $\mathrm{BJH}$ method in a pore range between 10 and $1000 \AA$ A. TG/DTG analyses were performed in a Shimadzu DTG-60H thermobalance, using alumina pan and sample mass of approximately $5 \mathrm{mg}$, at a heating rate of $10{ }^{\circ} \mathrm{C} \cdot \mathrm{min}^{-1}$, from room temperature to $800{ }^{\circ} \mathrm{C}$, under air atmosphere with a flow rate of $50 \mathrm{~mL} \cdot \mathrm{min}^{-1}$. Fourietransform infrared (FTIR) spectra were collected in the region of $4000-400 \mathrm{~cm}^{-1}$ using a Thermo Scientific FTIR Nicolet IS10 spectrometer, operated at room temperature; the samples were prepared as $\mathrm{KBr}$ pellets.

\section{RESULTS AND DISCUSSION}

$X$-ray diffractometry: Fig. 1 shows the diffractograms of the synthesized and calcined SBA-type structures. The XRD pattern of the M1 sample showed three peaks, which were indexed as the Bragg reflections (100), (110), and (200), typical of the hexagonal structure $(\mathrm{p} 6 \mathrm{~mm})$ of mesoporous silica SBA-15 [12]. This material was thermally stable because after calcining the maintenance of the well-defined hexagonal profile was verified. The diffractograms of samples M2 and M5 only showed the presence of two peaks referring to planes (100) and (211), the same described by Grudzien et al. [13], who studied the synthesis of SBA16 at 80,90 and $100{ }^{\circ} \mathrm{C}$. The authors reported that with the increase of the synthesis temperature the resolution quality of the XRD profiles of the materials decreased and a lower intensity of the peaks was noticed due to a smaller dispersion and ordering of the particles, but disclosed that the structures had a bicontinuous $\operatorname{Im} 3 \mathrm{~m}$ symmetry of bodycentered cubic, thus confirming the structure of the SBA- 16 . The XRD profile of the M3 sample had two peaks in the $2 \theta$ region between $0.5^{\circ}$ and $2.2^{\circ}$ for the planes (100) and (200), whereas the M4 sample had two peaks between $0.5^{\circ}$ and $1.7^{\circ},(100)$ and $(110)$, indicating the formation in both cases of siliceous mesoporous materials with two-dimensional hexagonal $(\mathrm{p} 6 \mathrm{~m})$ structure. As in the case of SBA-16 samples, the high temperature studied may have suppressed some other peak of the XRD profiles that indicated the formation of another mesoporous structure of the SBA type, because according to [8], generally these types of triblock copolymers favor the formation of mesoporous materials of the SBA type with hexagonal structure.

The XRD patterns of the synthesized and calcined MCM structures are shown in Fig. 2. The sample M6 showed three well-resolved peaks indexed as (100), (110) and (200) indicating a hexagonal two-dimensional mesoporous structure $(\mathrm{p} 6 \mathrm{~m})$ attributed to MCM-41 mesoporous material type [14]. Through the diffractogram of sample M7, the formation of the peaks of planes (211), (220) and (321), characteristic of the MCM-48 mesoporous cubic structure (Ia3d), was observed [15]. For both samples, it was found that after the calcination there was a higher definition and the displacement in the $2 \theta$ region of the peaks due to the decrease in the spacing between the planes by the condensation of the silanol groups within the pores of the materials $[16,17]$. Table I presents the structural characteristics of the synthesized SBA and MCM samples. The sample M1 presented an interplanar distance $\mathrm{d}_{100}=10 \mathrm{~nm}, \mathrm{a}_{0}=13 \mathrm{~nm}$ and $\mathrm{W}_{\mathrm{d}}=4 \mathrm{~nm}$, values close to those described in the literature for SBA15 structure [18]. The SBA-16 samples presented similar results with $\mathrm{d}_{100}=13 \mathrm{~nm}, \mathrm{a}_{0}=17 \mathrm{~nm}$ and $\mathrm{W}_{\mathrm{d}}=5$ and $6 \mathrm{~nm}$ for
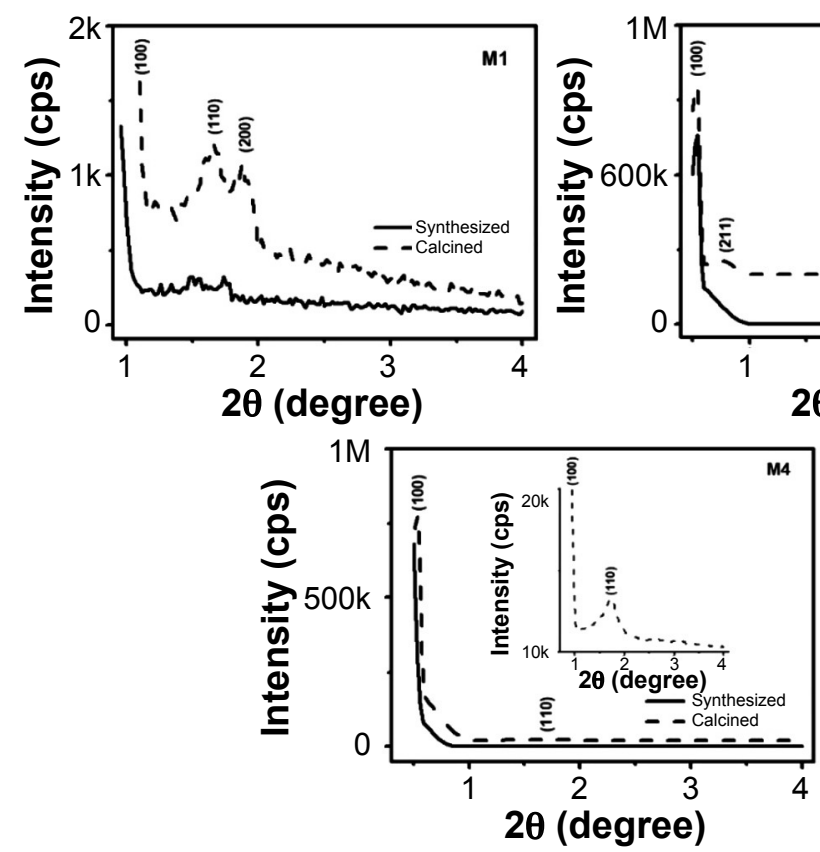
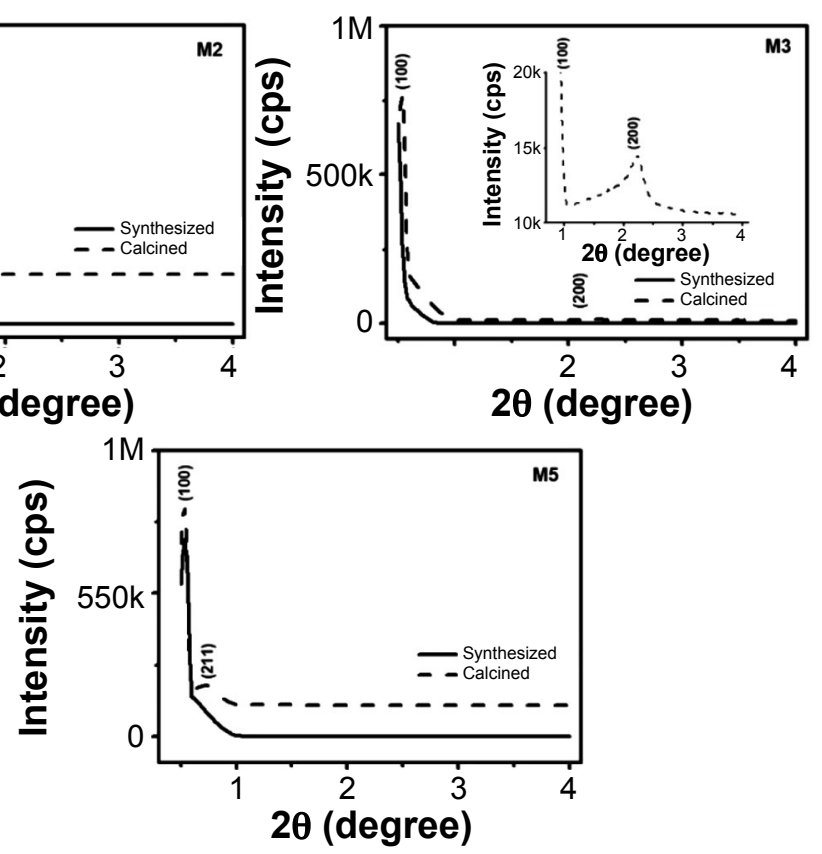

Figure 1: X-ray diffraction patterns of samples with SBA type structure.

[Figura 1: Difratogramas de raios $X$ das amostras de estrutura do tipo SBA.] 
M2 and M5, respectively, consistent with the values described in [19]. The samples that were synthesized with Brij O20 and Brij 93 presented values similar to those described previously, with $\mathrm{d}_{100}=9 \mathrm{~nm}, \mathrm{a}_{0}=1$ and $12 \mathrm{~nm}$ and $\mathrm{W}_{\mathrm{d}}=3$ and $4 \mathrm{~nm}$ for M3 and M4, respectively, an indication of materials of the class of SBA type mesoporous structures. The values obtained for the sample M6 compared to the values described in [20] are of the same magnitude for the MCM-41 structure, with $\mathrm{d}_{100}=4 \mathrm{~nm}, \mathrm{a}_{0}=9 \mathrm{~nm}$, and $\mathrm{W}_{\mathrm{d}}=5 \mathrm{~nm}$. The sample $\mathrm{M} 7$ presented values identical to those related to MCM-48 structure [21], with $\mathrm{d}_{211}=4 \mathrm{~nm}, \mathrm{a}_{0}=4 \mathrm{~nm}$, and $\mathrm{W}_{\mathrm{d}}=5 \mathrm{~nm}$.
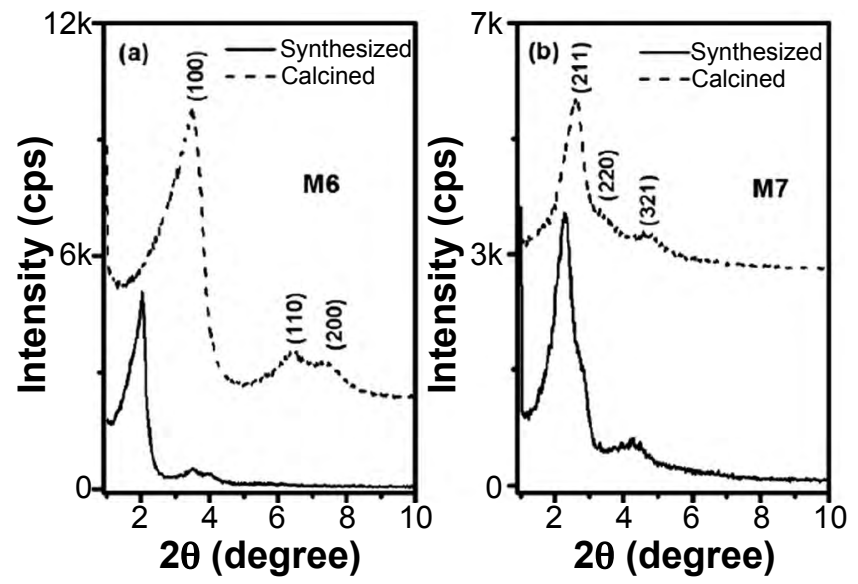

Figure 2: X-ray diffraction patterns of samples with MCM type structure.

[Figura 2: Difratogramas de raios $X$ das amostras de estrutura do tipo MCM.]

Table I - Textural properties obtained from XRD data. [Tabela I - Propriedades texturais obtidas de dados de DRX.]

\begin{tabular}{cccc}
\hline Sample & $\mathrm{d}_{\mathrm{hkl}}(\mathrm{nm})$ & $\mathrm{a}_{0}(\mathrm{~nm})$ & $\mathrm{W}_{\mathrm{d}}(\mathrm{nm})$ \\
\hline M1 & 10 & 13 & 4 \\
M2 & 13 & 17 & 5 \\
M3 & 9 & 11 & 3 \\
M4 & 9 & 12 & 4 \\
M5 & 13 & 17 & 6 \\
M6 & 4 & 9 & 5 \\
M7 & 4 & 4 & 1 \\
\hline
\end{tabular}

$d_{h k l}$ - interplanar distance (100) for samples M1 to M6 and (211) for sample $M 7 ; a_{0}$ - mesoporous structure parameter; $W_{d}$-thickness of the silica wall.

Nitrogen adsorption-desorption: the $\mathrm{N}_{2}$ adsorptiondesorption isotherms and the corresponding pore size distribution of the SBA type samples are shown in Fig. 3. All samples showed type IV isotherms [22]. The isotherms of samples M1, M2 and M5 exhibited a steep capillary condensation stage that occurred at relative pressures $\left(\mathrm{P} / \mathrm{P}_{0}\right)$ from 0.5 to 0.9 . The hysteresis that appeared in the multilayer range of the physisorption isotherms indicated capillary condensation in mesoporous structures. The curves showed $\mathrm{H} 2$ hysteresis loops with two branches almost vertical and parallel. According to the classification of IUPAC [23], this type is associated with porous materials consisting of approximately uniform rod-like particle agglomerates or compacts in a very regular matrix. The M1 sample presented a pore size distribution between 5 and $10 \mathrm{~nm}$, whereas samples M2 and M5 presented a wider distribution in the range of 2 to $20 \mathrm{~nm}$. The isotherms of M3 and M4 showed a less steep capillary condensation stage in a lower $\mathrm{P} / \mathrm{P}_{0}$ range, from 0.3 to 0.7 , indicating the low pressure required for capillary condensation due to the formation of small pores. Both samples showed a similar pore size distribution in the 2 to $4 \mathrm{~nm}$ range. In addition, the hysteresis loop was of type $\mathrm{H} 2$, indicating that pore stacking formed slit-shaped cavities that are generally induced by the irregular morphology of mesoporous silica. The $\mathrm{N}_{2}$ adsorption-desorption isotherms of the MCM type samples are illustrated in Fig. 4, corresponding to type IV isotherms, which are typical of mesoporous molecular sieves like MCM structure, with well-defined and ordered cylindrical mesopores. The isotherms had three well-defined stages, identified as: i) at low relative pressures $\left(\mathrm{P} / \mathrm{P}_{0}<0.25\right), \mathrm{N}_{2}$ adsorption increased slowly, attributed to the monolayer-multilayer adsorption on the pore walls; ii) at intermediate relative pressures $\left(0.25<\mathrm{P} / \mathrm{P}_{0}<0.40\right)$, a marked inflection was possibly related to capillary condensation within small pores, termed primary mesopores; and iii) at high relative pressures $\left(\mathrm{P} / \mathrm{P}_{0}>0.4\right)$ a plateau with a slight slope was observed, attributed to the multilayer adsorption of $\mathrm{N}_{2}$ molecules on the external surface of the crystals [24]. It was observed that both samples had a uniform and unimodal pore size distribution (approximately 2 to $4 \mathrm{~nm}$ ).

Table II summarizes the textural properties obtained by $\mathrm{N}_{2}$ adsorption-desorption of the calcined MCM and SBA samples. The sample M6 presented values of $0.77 \mathrm{~cm}^{3} \cdot \mathrm{g}^{-1}$ for pore volume and $\mathrm{D}_{\mathrm{BJH}}=4 \mathrm{~nm}$, which were coherent with those described for MCM-41 structure in the literature, in contrast, presented a low area value $\left(765 \mathrm{~m}^{2} \cdot \mathrm{g}^{-1}\right)$ compared to that described by Perez et al. [25], which report areas for these materials of about $1160 \mathrm{~m}^{2} \cdot \mathrm{g}^{-1}$; this may be due to the pore size of this sample $(4 \mathrm{~nm})$, since materials with larger pores have the tendency to show a smaller surface area. The sample M7 presented a high surface area $A_{B E T}=997 \mathrm{~m}^{2} \cdot \mathrm{g}^{-1}$, with $\mathrm{V}_{\mathrm{p}}=0.79 \mathrm{~cm}^{3} \cdot \mathrm{g}^{-1}$ and $\mathrm{D}_{\mathrm{BJH}}=3 \mathrm{~nm}$, values similar to those described in the literature for the MCM-48 synthesized by the adopted methodology [17]. The M1 sample showed higher textural parameter values as compared to those reported in [26], with $\mathrm{A}_{\mathrm{BET}}=795 \mathrm{~m}^{2} \cdot \mathrm{g}^{-1}, \mathrm{~V}_{\mathrm{p}}=0.99 \mathrm{~cm}^{3} \cdot \mathrm{g}^{-1}$, and $\mathrm{D}_{\mathrm{BJH}}=6 \mathrm{~nm}$, demonstrating optimal conditions for obtaining the SBA-15 mesoporous structure. The values of the textural parameters described in [27] for the SBA-16 structure indicated that the values obtained for $A_{B E T}=858$ and $711 \mathrm{~m}^{2} \cdot \mathrm{g}^{-1}, \mathrm{~V}_{\mathrm{p}}=1.06$ and $1.35 \mathrm{~cm}^{3} \cdot \mathrm{g}^{-1}$ and $\mathrm{D}_{\mathrm{BJH}}=5$ and $7 \mathrm{~nm}$ for samples $\mathrm{M} 2$ and $\mathrm{M} 5$, respectively, were consistent with the literature. The samples M3 and M4 had the best surface area results of the synthesized structures, 1074 and $1075 \mathrm{~m}^{2} \cdot \mathrm{g}^{-1}$, respectively, and, in comparison to the other samples, they showed a tendency that 

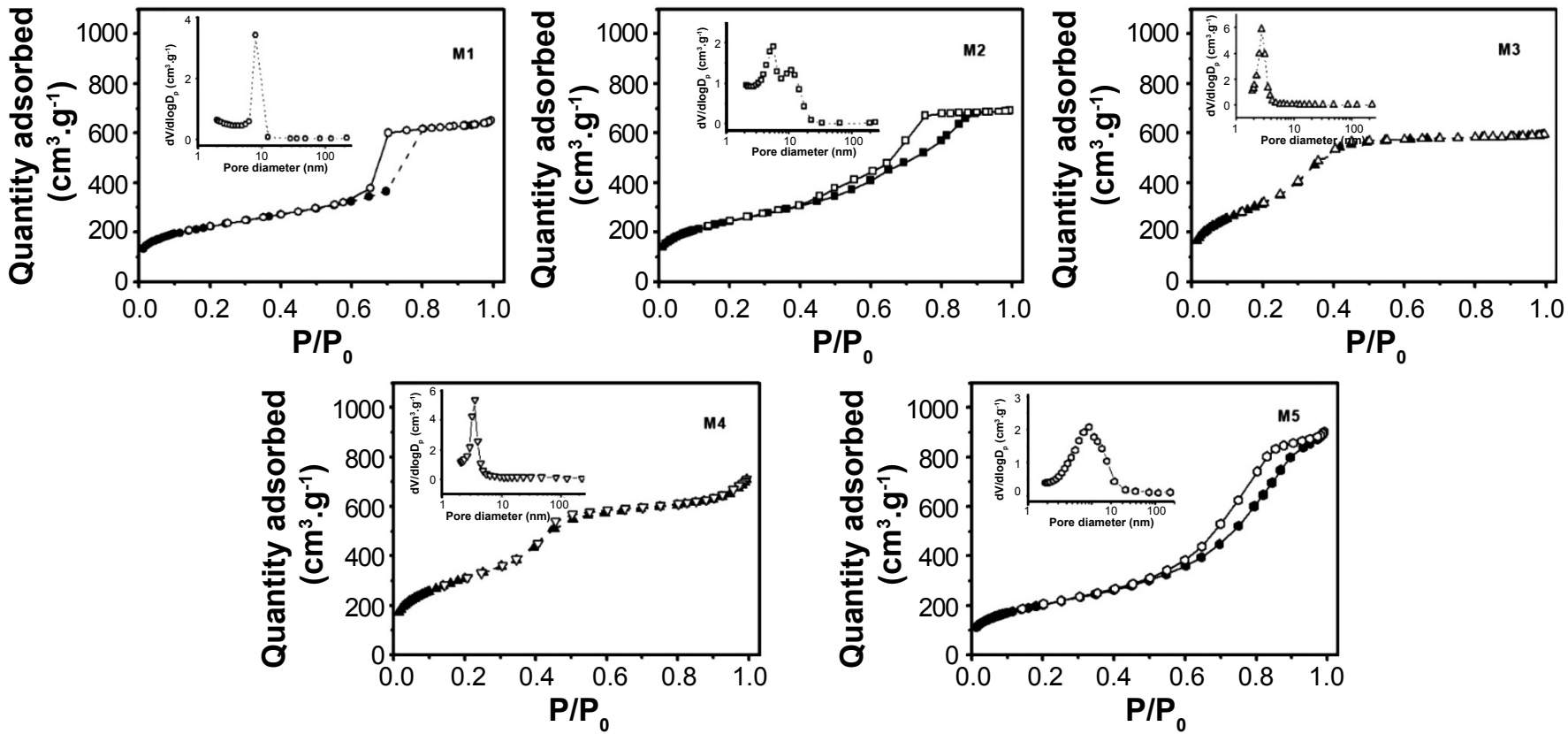

Figure 3: $\mathrm{N}_{2}$ adsorption-desorption isotherms and pore size distribution curves of SBA type materials.

[Figura 3: Isotermas de adsorção-dessorção de $\mathrm{N}_{2}$ e curvas de distribuição de tamanho de poros dos materiais do tipo SBA.]
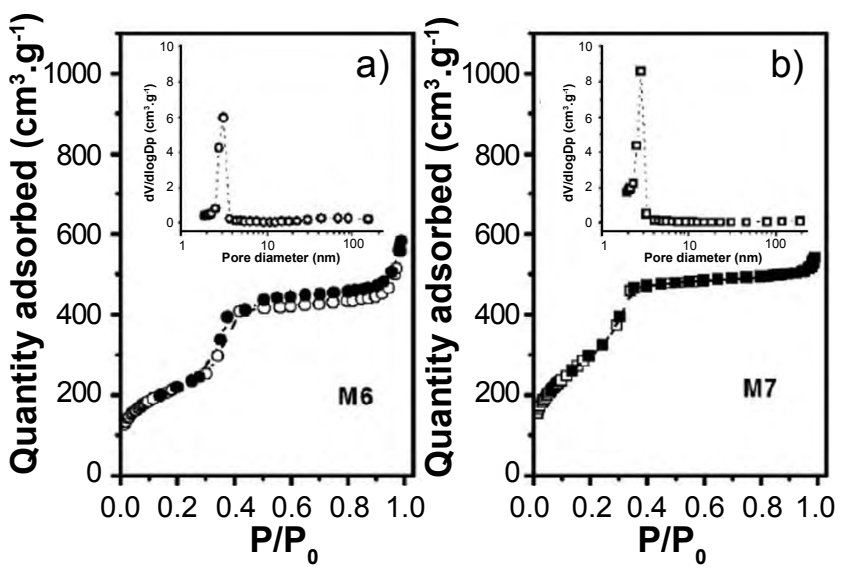

Figure 4: $\mathrm{N}_{2}$ adsorption-desorption isotherms and pore size distribution curves of MCM type materials.

[Figura 4: Isotermas de adsorção-dessorção de $\mathrm{N}_{2}$ e curvas de distribuição de tamanho de poros dos materiais do tipo MCM.]

Table II - Textural properties obtained by nitrogen adsorption-desorption.

[Tabela II - Propriedades texturais obtidas por adsorçãodessorção de nitrogênio.]

\begin{tabular}{cccc}
\hline Sample & $\begin{array}{c}\mathrm{A}_{\mathrm{BET}} \\
\left(\mathrm{m}^{2} \cdot \mathrm{g}^{-1}\right)\end{array}$ & $\begin{array}{c}\mathrm{V}_{\mathrm{p}} \\
\left(\mathrm{cm}^{3} \cdot \mathrm{g}^{-1}\right)\end{array}$ & $\begin{array}{c}\mathrm{D}_{\mathrm{BJH}} \\
(\mathrm{nm})\end{array}$ \\
\hline M1 & 795 & 0.99 & 6.0 \\
M2 & 858 & 1.06 & 5.0 \\
M3 & 1074 & 0.91 & 3.0 \\
M4 & 1075 & 1.04 & 4.0 \\
M5 & 711 & 1.35 & 7.0 \\
M6 & 765 & 0.77 & 4.0 \\
M7 & 997 & 0.79 & 3.0 \\
\hline
\end{tabular}

$A_{B E T}$ - specific surface area; $V_{p}$ - pore volume; $D_{B J H}$ - pore diameter. samples with smaller pores presented bigger surface areas and vice-versa.

Thermogravimetric analyses (TG/DTG): Fig. 5 shows the TG curves of the SBA type mesoporous materials, where they typically presented three mass losses in the same temperature ranges indicated in [28]. The first event occurred approximately from room temperature to $243{ }^{\circ} \mathrm{C}$, with mass losses of 35\% (M1), 3\% (M2), $0.5 \%(\mathrm{M} 3), 20 \%$ (M4) and 6\% (M5). This first event was attributed to the loss of adsorbed water. The second event occurred in the range of 243 to 490 ${ }^{\circ} \mathrm{C}$, with mass losses of $22 \%$ (M1), $15 \%$ (M2), $37 \%$ (M3), $26 \%$ (M4) and $41 \%$ (M5) due mainly to the decomposition of the surfactant. Then, the third event occurred with losses of $11 \%$ (M1), 2\% (M2), 10\% (M3), 6\% (M4) and 9\% (M5), probably due to the condensation of silanols. The DTG (derivative of TG) profile showed intense peaks in the decomposition region of organic surfactants, demonstrating a strong interaction of these compounds with the walls of SBA structures. The TG curves of samples M6 and M7 are shown in Fig. 6. The thermogravimetric analyses showed three mass loss events as a function of temperature increase. From room temperature to $132{ }^{\circ} \mathrm{C}$ range, the mass loss was $2 \%$ (M6) and $0.7 \%$ (M7), and was associated with the desorption of water from the external surface and removal of the occluded water in the mesopores; from 132 to $326^{\circ} \mathrm{C}$, the mass loss was $25 \%$ (M6) and $32 \%$ (M7), which was related to the oxidative decomposition and removal of the organic species (surfactant and precursors); above $326^{\circ} \mathrm{C}$ the mass loss was $7 \%$ (M6) and $13 \%$ (M7), attributed to the decomposition of the remnants of the organic compounds, as well as related to water loss due to the condensation of adjacent silanol groups (Si-OH) to form siloxane bonds or the elimination of residual ethoxy groups due to hydrolysis of TEOS (in the case of the M7 sample) [29]. The DTG curves of both samples showed 

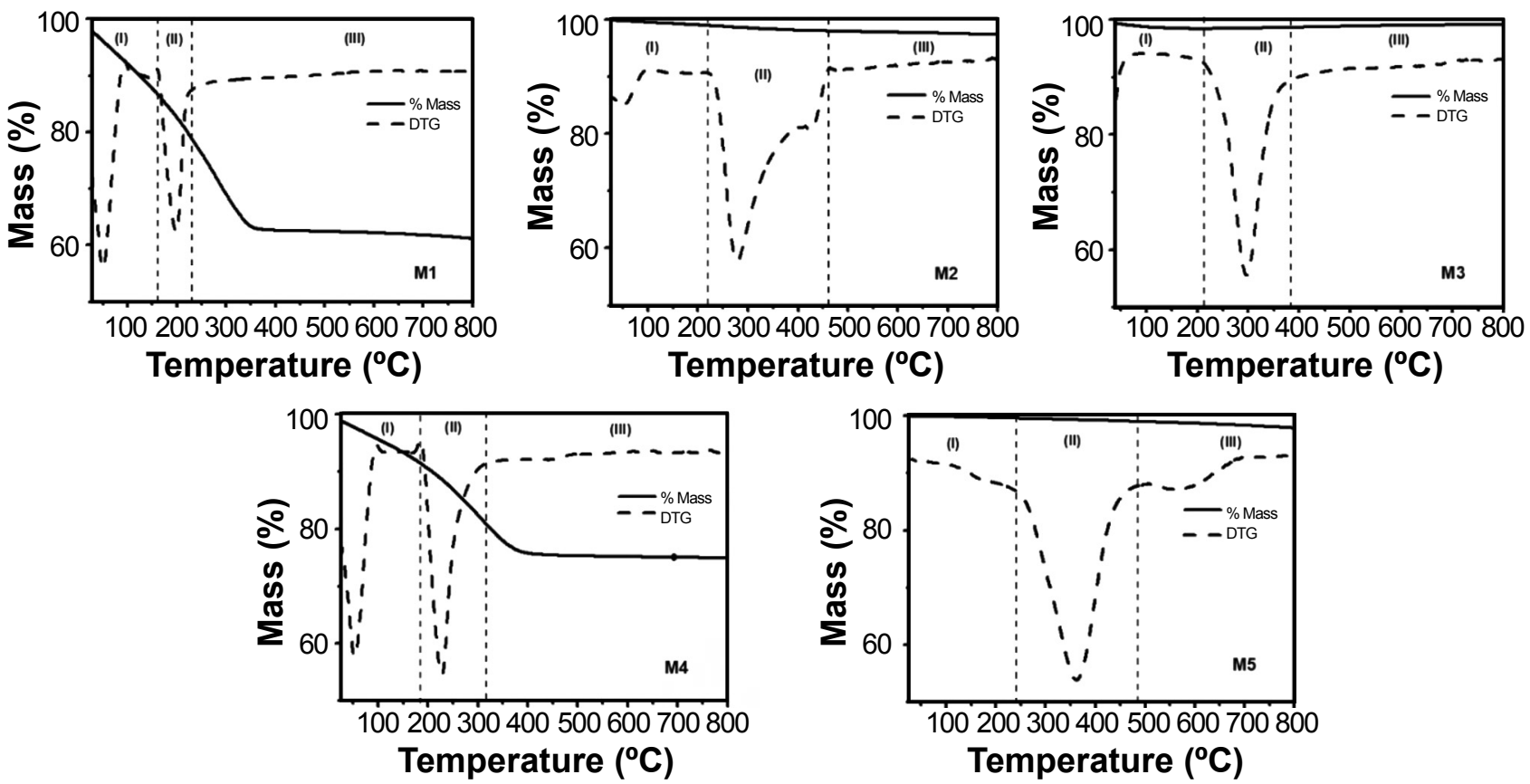

Figure 5: Thermogravimetric curves of samples with SBA type structure.

[Figura 5: Curvas termogravimétricas das amostras de estrutura do tipo SBA.]
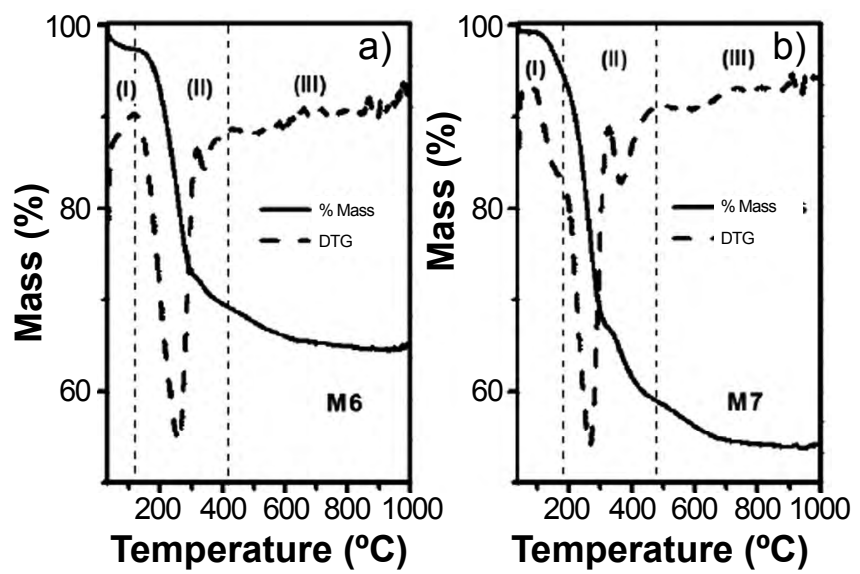

Figure 6: Thermogravimetric curves of samples with MCM type structure.

[Figura 6: Curvas termogravimétricas das amostras de estrutura do tipo MCM.]

similar profiles in relation to the position of the peaks with temperature. However, peak intensities may differ due to the difference in gel composition [1].

Fourier-transform infrared spectroscopy (FTIR): Fig. 7 shows the absorption spectra in the infrared region in the 4000$400 \mathrm{~cm}^{-1}$ range for the SBA and MCM type structures in the uncharged form. The presence of a $1069 \mathrm{~cm}^{-1}$ frequency band corresponding to the asymmetrical stretching attributed to $\mathrm{Si}$ O-Si groups was observed in all spectra of SBA type materials. The vibrational bands at 460 and $802 \mathrm{~cm}^{-1}$ corresponded to the Si-O-Si symmetrical stretching of the materials. An absorption band at $956 \mathrm{~cm}^{-1}$ corresponded to the stretching of the silanol (Si-OH) groups present inside the mesopores. Bands in the range of $1330-1500 \mathrm{~cm}^{-1}$ and at around 2868 and $2933 \mathrm{~cm}^{-1}$ referred
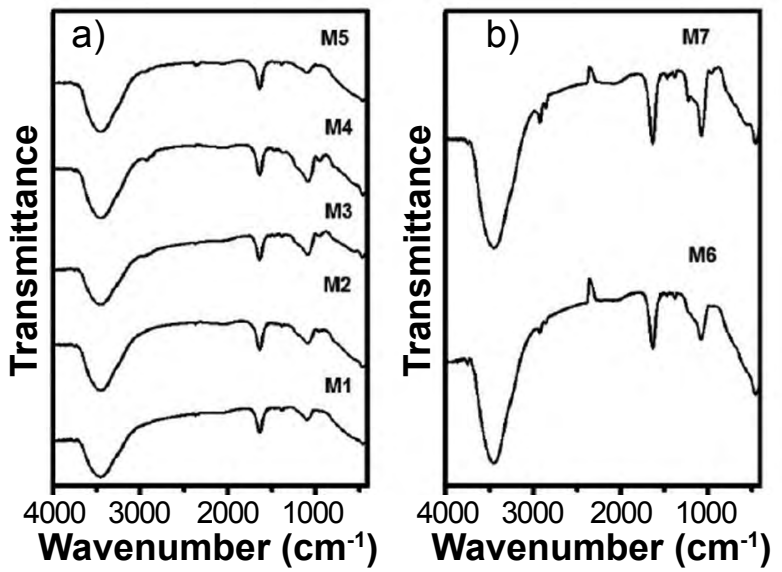

Figure 7: FTIR spectra of the structures: a) SBA; and b) MCM. [Figura 7: Espectros de FTIR das estruturas: a) SBA; e b) MCM.]

to the deformations of the copolymers and the symmetrical and asymmetric stretches between the $\mathrm{C}-\mathrm{H}$ bonds of the $\mathrm{CH}_{2}$ groups, respectively. A vibrational band at $1229 \mathrm{~cm}^{-1}$ corresponding to the asymmetric stretches of the Si-O bond of the materials $[30,31]$ was observed. In both spectra for the MCM type materials, characteristic bands referring to stretches and deformations of the organic template $\mathrm{CTMA}^{+}$ functional groups, as well as of the inorganic functional groups of the structures, were observed. The vibrational bands in the range 2924-2856 cm-1 were attributed to stretches of $\mathrm{CH}$ bonds of the $\mathrm{CH}_{2}$ and $\mathrm{CH}_{3}$ groups in the $\mathrm{CTMA}^{+}$species. The band observed at $1484 \mathrm{~cm}^{-1}$ referred to the asymmetric deformation of the methyl group in the $\mathrm{CH}_{3}-\mathrm{N}^{+}$. Vibrational frequencies at around 1240,1092, 800 and $466 \mathrm{~cm}^{-1}$ are 
typical of the Si-O bond of the condensed silica framework. The band at around $1644 \mathrm{~cm}^{-1}$ was mainly attributed to the angular vibrations of water molecules adsorbed on the surface of the materials. The samples exhibited a band at around 964 $\mathrm{cm}^{-1}$, which was associated with symmetrical vibrational stretches of the Si-OH groups. A broad band in the $3466 \mathrm{~cm}^{-1}$ region can be attributed to the hydroxyl groups of the structure interacting with water molecules by hydrogen bonds $[32,33]$. The presence of band at $3456 \mathrm{~cm}^{-1}$ relative to internal and external hydroxyl groups interacting with water molecules by hydrogen bonds was observed in all materials, and the band at $1644 \mathrm{~cm}^{-1}$ was attributed to the angular vibrations of adsorbed water molecules on the solid surface.

\section{CONCLUSIONS}

In view of the XRD results, the synthesis of the mesoporous silica structures of MCM and SBA types was effective in obtaining the desired materials, which presented the characteristic peaks of these structures. Through the results of $\mathrm{N}_{2}$ adsorption-desorption, type IV isotherms were obtained with hysteresis type $\mathrm{H} 2$, with values of area and volume corresponding to mesoporous materials; the best results of specific surface area were obtained for the structures synthesized with the surfactants Igepal CO630 and Brij O20. TG/DTG analyses showed that all materials presented three mass loss events. The FTIR spectra presented characteristic absorption bands of MCM and SBA type materials. Therefore, it was possible to obtain materials with specific characteristics using different types of surfactant.

\section{ACKNOWLEDGMENTS}

To the LSCat (Laboratory of Catalysts Synthesis) of the Federal University of Alagoas and Coordenação de Aperfeiçoamento de Pessoal de Nível Superior (CAPES) for the financial support.

\section{REFERENCES}

[1] J.S. Beck, J.C. Vartulli, W.J. Roth, M.E. Leonowicz, C.T. Kresge, K.D. Schmitt, C.T.-W. Chu, D.H. Olson, E.W. Sheppard, S.B. Mccullen, J.B. Higgins, J.L. Schlenker, J. Am. Chem. Soc. 114 (1992) 10834.

[2] N. Rahmat, A.Z. Abdullah, A.R. Mohamed, Am. J. Appl. Sci. 12 (2010) 1579.

[3] A.C. Pierre, Introduction to sol-gel processing, Kluwer Acad. Publ., Boston (1998).

[4] B. Naik, N.N. Ghosh, Recent Pat. Nanotechnol. 3 (2009) 213.

[5] F. Hoffmann, M. Cornelius, J. Morell, M. Froba, Angew. Chem. 46 (2006) 3216.

[6] S. Bhattacharyya, G. Lelong, M.-L. Saboungi, J. Exp. Nanosci. 1 (2007) 375.

[7] J. Xu, Z. Luan, H. He, W. Zhou, L. Kevan, Chem. Mater. 10 (1998) 3690.

[8] D. Zhao, Q. Huo, J. Feng, B.F. Chmelka, G.D. Stucky, J.
Am. Chem. Soc. 120 (1998) 6024.

[9] T. Linssen, K. Cassiers, P. Cool, E.F. Vansant, Adv. Colloid Interface Sci. 103 (2003) 121.

[10] L.L. Pérez, E.R.H. Van Eck, I. Melian-Cabrera, Microporous Mesoporous Mater. 220 (2016) 88.

[11] A. Doyle, B.K. Hodnett, Microporous Mesoporous Mater. 63 (2003) 53.

[12] A.R. Nascimento, G.P. Figueredo, G. Rodrigues, M.A.F. Melo, M.J.B. Souza, D.M.A. Melo, Cerâmica 60, 356 (2014) 482.

[13] R.M. Grudzien, B.E. Grabicka, M. Jaroniec, Appl. Surf. Sci. 253 (2007) 5660.

[14] P.J. Bruinsma, A.Y. Kim, J. Liu, S. Baskaran, Chem. Mater. 9 (1997) 2507.

[15] P. Van Der Voort, M. Mathieu, F. Mees, E.F. Vansant, J. Phys. Chem. 102 (1998) 8847.

[16] H.I. Meléndez-Ortizn, Y.A. Perera-Mercado, L.A. García-Cerda, J.A. Mercado-Silva, G. Castruita, Ceram. Int. 40 (2014) 9701.

[17] D. Matei, D.L. Cursaru, S. Mihai, Dig. J. Nanomater. Biostruct. 11 (2016) 271.

[18] B. Erdem, S. Erdem, R.M. Öksüzoğlu, A. Çitak, J. Porous Mater. 20 (2013) 1041.

[19] C. Zhengkai, D. Peng, D. Aijun, G. Rong, Z. Zhen, L. Hong, P.Z. Zhang, X. Chunming, C. Zhentao, Chem. Eng. Sci. 155 (2016) 141.

[20] K. Zhang, E.-H. Yuan, L.-L. Xu, Q.-S. Xue, C. Luo, B. Albela, L. Bonneviot, Eur. J. Inorg. Chem. 26 (2012) 43.

[21] K. Schumacher, P.I. Ravikovitch, A.D. Chesne, A.V. Neimark, K.K. Unger, Langmuir 16 (2000) 4648.

[22] G. Chandrasekar, K.S. You, J.W. Ahn, W.S. Ahn, Microporous Mesoporous Mater. 111 (2008) 455.

[23] K.S.W. Sing, D.H. Everett, R.A.W. Haul, L. Moscou, R.A. Pierotti, J. Rouquerol, T. Siemieniewska, Pure Appl. Chem. 57 (1985) 603.

[24] C.Y. Chen, H.L. Li, M.E. Davis, Microporous Mesoporous Mater. 2 (1993) 17.

[25] L.L. Perez, E.R.H. Van Eck, I. Melian-Cabrera, Microporous Mesoporous Mater. 220 (2016) 88.

[26] J. Wang, H. Ge, W. Bao, Mater. Lett. 145 (2015) 312.

[27] A. Feliczak-Guzik, B. Jadach, H. Piotrowska, M. Murias, J. Lulek, I. Nowak, Microporous Mesoporous Mater. 220 (2016) 231.

[28] L. Xiao, J. Li, H. Jin, R. Xu, Microporous Mesoporous Mater. 96 (2006) 413.

[29] N. La-Salvia, J J. Lovón-Quintana, A.S.P. Lovóna, G.P. Valença, Mater. Res. 20 (2017) 1461.

[30] N.B.A. Rahman, H.M. Rasid, H.M. Hassan, M.N. Jalil, Malaysian J. Anal. Sci. 20 (2016) 539.

[31] S.B. Shete, U.D. Joshi, J. Appl. Phys. 7 (2015) 50.

[32] M. Broyer, S. Valange, J.P. Bellat, O. Bertrand, G. Weber, Z. Gabelica, Langmuir 18 (2002) 5083.

[33] M.J.B. Souza, A.O.S. Silva, J.M.F.B. Aquino, V.J. Fernandes Jr, A.S. Araújo, J. Therm. Anal. Calorim. 75 (2004) 693.

(Rec.19/09/2018, Rev.04/12/2018, 19/02/2019, 14/05/2019, Ac. 19/05/2019) 